Int. J. Electrochem. Sci., 16 (2021) Article ID: 210761

International Journal of

ELECTROCHEMICAL

SCIENCE

www.electrochemsci.org

\title{
Sensitive Electrochemical Detection of Caffeic Acid using a Carboxyl-Functionalized Reduced Graphene Oxide-Modified Glassy Carbon Electrode (ERGO-COOH/GCE)
}

\author{
Ming Zhou, Yong Xu, Rong Zhong, Yurong Wang* \\ School of Pharmaceutical Sciences, Zhejiang Chinese Medical University, Hangzhou 310053, China \\ *E-mail: wangyr@zcmu.edu.cn
}

doi: $10.20964 / 2021.07 .60$

Received: 17 March 2021 / Accepted: 29 April 2021 / Published: 31 May 2021

\begin{abstract}
A glassy carbon electrode modified by carboxyl-functionalized reduced graphene oxide (ERGO$\mathrm{COOH} / \mathrm{GCE}$ ) was developed by electrochemical deposition method. The electrochemical behavior of caffeic acid (CA) on the ERGO-COOH/GCE was studied, and an electroanalytical method for the detection of $\mathrm{CA}$ in tablets was established. The effects of the modification parameters, the $\mathrm{pH}$ of the buffer solution and the scanning rate on the electrochemical behavior of CA were investigated by cyclic voltammetry $(\mathrm{CV})$. The results revealed that modifying the GCE by electrochemical deposition facilitated a more sensitive response to $\mathrm{CA}$ on the modified electrode than modifying it by drop coating. The peak current of CA on the ERGO-COOH/GCE was significantly higher than that on the bare glassy carbon electrode (GCE) over five scan cycles, and the optimized the concentration of GO-COOH, the scanning cycles, and the $\mathrm{pH}$ were $4 \mathrm{mg} \cdot \mathrm{mL}^{-1}, 5$ cycles, and 2.0 , respectively. The redox reaction of CA on the modified electrode was a quasi-reversible process controlled by adsorption and involved the transfer of two electrons and two protons. The ERGO-COOH/GCE showed a linear response to CA in the range of $0.05 \sim 20 \mu \mathrm{M}$ with a limit of detection of $8 \mathrm{nM}(S / N=3)$. The modified electrode exhibited good repeatability and reproducibility and anti-interference performance. The ERGO-COOH/GCE was applied to the detection of CA in caffeic acid tablets with a recovery of $97.7 \% \sim 108 \%$.
\end{abstract}

Keywords: Caffeic acid; electrochemical deposition; ERGO-COOH/GCE; modified electrode; differential pulse voltammetry

\section{$\underline{\text { FULL TEXT }}$}

(C) 2021 The Authors. Published by ESG (www.electrochemsci.org). This article is an open access article distributed under the terms and conditions of the Creative Commons Attribution license (http://creativecommons.org/licenses/by/4.0/). 